\title{
PENGARUH KUALITAS PELAYANAN JASA TERHADAP KEPUASAN PELANGGAN PADA KANTOR NOTARIS DAN PPAT RACHMANSYAH PURBA SH, M.KN DI KOTA PEMATANGSIANTAR
}

\author{
Oleh: \\ Debi Eka Putri \\ S1 Manajemen \\ Darwin Lie, Efendi, Ady Inrawan
}

Abstraksi

Judul penelitian ini adalah Pengaruh Kualitas Pelayanan Jasa Terhadap Kepuasan Pelanggan Pada Kantor Notaris dan PPAT Rachmansyah Purba SH, M.Kn di Kota Pematangsiantar. Penelitian ini dilakukan dengan menggunakan metode analisa deskriptif kualitatif dan analisa deskriptif kuantitatif. Adapun populasi yang digunakan penulis dalam penelitian ini adalah sebanyak 40 responden yaitu rekanan, dalam hal ini pegawai Bank bagian unit pembiayaan dan developer perumahan pada bulan Juli-Agustus 2014. Pengumpulan data dilakukan dengan wawancara, dokumentasi, kuesioner dan observasi. Tehnik analisa yang digunakan ialah regresi linier sederhana, koefisien korelasi, determinasi dan uji t.

Hasil penelitian dapat disimpulkan sebagai berikut: 1) Pelanggan menyatakan kualitas pelayanan jasa baik dan kepuasan pelanggan dikategorikan puas. 2) Hasil pengujian regresi adalah $\hat{\mathrm{Y}}=24,474+0,519 \mathrm{X}$ berarti kualitas pelayanan jasa berpengaruh positif terhadap kepuasan pelanggan. 3) Hasil $\quad r=0,609$ artinya terdapat hubungan yang kuat dan positif antara kualitas pelayanan jasa dan kepuasan pelanggan pada Kantor Notaris dan PPAT Rachmansyah Purba, SH, M.Kn di Kota Pematangsiantar. Tinggi rendahnya kepuasan pelanggan dapat dijelaskan oleh kualitas pelayanan jasa sebesar 37,1\%. 4) Hipotesis penelitian $\mathrm{H}_{0}$ ditolak dan $\mathrm{Ha}$ diterima, artinya kualitas pelayanan berpengaruh positif dan signifikan terhadap kepuasan pelanggan pada Kantor Notaris dan PPAT Rachmansyah Purba SH, M.Kn di Kota Pematangsiantar.

Kata kunci: Kualitas Pelayanan Jasa dan Kepuasan Pelanggan

\section{Abstraction}

The title of this research is The Influence Of Service Quality To Customer Satisfaction At Notaries And PPAT Rachmansyah Purba SH, M.Kn Office At Pematangsiantar. This research is done by using qualitative descriptive analysis and quantitative descriptive analysis. The populations of this research are 40 respondents, there are partners, such as bank officer at detrayal unit and developer on July-August 2014. The collecting data by interview, documentation, questionnaires and observation. The analysis technique's by simple regression analysis, correlation coeficient, determination, and t test.

Result of inferential research as follows: 1) Customer expressed service quality have goodness and customer satisfaction categorized satisfied. 2) Test results the regression is $\hat{Y}=24,474+0,519 X$ means the positive influence service quality to customer satisfaction. 3) Results of $r=0,609$ means there are strength relationship and positive of service quality to customer satisfaction at Notaries and PPAT Rachmansyah Purba SH, M.Kn Office at Pematangsiantar. High low customer satisfaction can be explained by service quality equal to $\quad 37,1 \%$. 4) Hypothesis research $H_{0}$ is rejected and Ha is received mean that service quality gives positive influence and significant to customer satisfaction at Notaries and PPAT Rachmansyah Purba SH, M.Kn Office at Pematangsiantar.

Keywords : Service Quality and Customer Satisfaction

\section{A. PENDAHULUAN}

\section{Latar Belakang Masalah}

Para praktisi pemasaran telah menyadari betapa pentingnya kepuasan pelanggan yang bergantung pada kualitas pelayanan yang ditawarkan sebagai salah satu kunci keberhasilan suatu perusahaan. Salah satu perusahaan jasa yang terus menerus berkembang di bidang hukum, salah satunya yaitu kantor Notaris dan PPAT. Kantor Notaris dan PPAT Rachmansyah Purba, SH, M.Kn di Pematangsiantar merupakan perusahaan swasta yang bergerak di bidang jasa pelayanan hukum. Mengingat yang dikelola oleh Kantor Notaris dan PPAT adalah pelayanan maka kualitas pelayanan yang baik mutlak dilakukan agar dapat meningkatkan kepuasan bagi para pelanggannya.

Berikut adalah dugaan sementara ataupun pengamatan alasan pelanggan merasa cukup puas, yaitu sebagai berikut: 
Tabel 1

Fenomena Kepuasan Pelanggan Kantor Notaris dan PPAT Rachmansyah Purba, SH, M.Kn di Kota Pematangsiantar

Periode Maret-Juni tahun 2014

\begin{tabular}{|c|c|c|c|c|}
\hline Ne & $\begin{array}{l}\text { Kepuasain } \\
\text { Pelanggan }\end{array}$ & $\begin{array}{c}\text { Yang } \\
\text { Seharuaya }\end{array}$ & $\begin{array}{c}\text { Yang } \\
\text { Terbakuna }\end{array}$ & $\begin{array}{l}\text { Kondiai } \\
\text { Kepuarai } \\
\text { Pelangran }\end{array}$ \\
\hline 1 & Prosedur pelaryan & \multirow{5}{*}{ 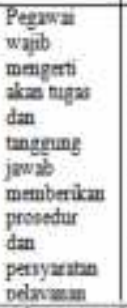 } & \multirow{5}{*}{ 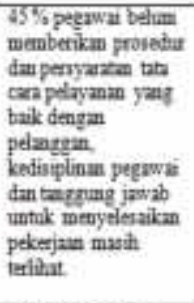 } & \multirow{5}{*}{ 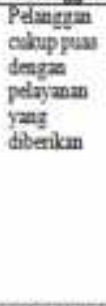 } \\
\hline 2. & Penyoricen poliyamin & & & \\
\hline 3. & $\begin{array}{l}\text { Kopdasan pethugas } \\
\text { pelwymin }\end{array}$ & & & \\
\hline 4 & 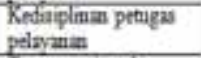 & & & \\
\hline 3. & 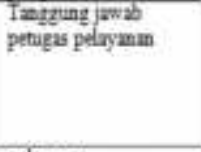 & & & \\
\hline & petsyan & \multirow{3}{*}{ 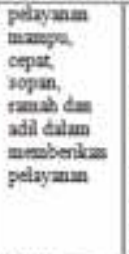 } & \multirow{3}{*}{ 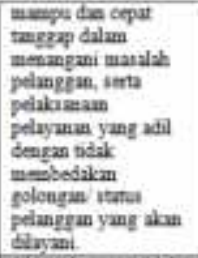 } & \multirow{3}{*}{ 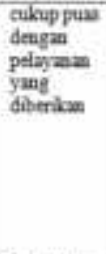 } \\
\hline 5. & 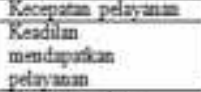 & & & \\
\hline 9. & 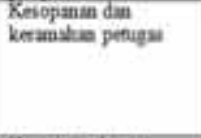 & & & \\
\hline 70 & $\begin{array}{l}\text { Kerayarm bays } \\
\text { pelaymin }\end{array}$ & \multirow{2}{*}{$\begin{array}{l}\text { Bixyzyant } \\
\text { wajar dm } \\
\text { paih dalam } \\
\text { mestapat } \\
\text { layanan }\end{array}$} & \multirow{2}{*}{ 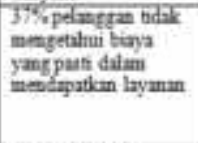 } & \multirow{2}{*}{ 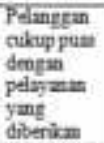 } \\
\hline 11. & 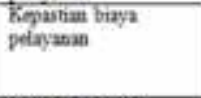 & & & \\
\hline 12 & $\begin{array}{l}\text { Repputial jadwi } \\
\text { pelosinan }\end{array}$ & \multirow{3}{*}{$\begin{array}{l}\text { Jadwalyal } \\
\text { seruai, seets } \\
\text { bamanan } \\
\text { das } \\
\text { kerymanan } \\
\text { selama } \\
\text { pelyyan }\end{array}$} & \multirow{3}{*}{ 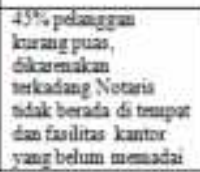 } & \multirow{3}{*}{$\begin{array}{l}\text { Pedangzati } \\
\text { cukuppuas } \\
\text { deugzan } \\
\text { pelsyeat } \\
\text { yang } \\
\text { diberilim }\end{array}$} \\
\hline 12 & $\begin{array}{l}\text { Renymanan } \\
\text { linviongan }\end{array}$ & & & \\
\hline 14. & $\begin{array}{l}\text { Keamimana } \\
\text { peloyanim }\end{array}$ & & & \\
\hline
\end{tabular}

Sumber: hasil wawancara

Dari tabel fenomena di atas terlihat bahwa kondisi kepuasan pelanggan berada dalam kategori cukup puas. Hal itu disebabkan dimensi kualitas pelayanan seperti keandalan (reliability) misalnya dalam hal waktu kecepatan penyelesaian, jaminan (assurance) misalnya dalam hal kepercayaan, bukti fisik (tangibles) misalnya dalam hal fasilitas kantor, empati (emphaty) misalnya dalam hal pemahamam kebutuhan secara spesifik dan daya tanggap (responsiveness) misalnya dalam hal kejelasan informasi dari pegawai.

\section{Rumusan Masalah}

Berdasarkan uraian di atas, adapun rumusan masalah mengenai Kualitas Pelayanan Jasa dan Kepuasan Pelanggan adalah sebagai berikut :

a. Bagaimana gambaran Kualitas Pelayanan Jasa dan Kepuasan Pelanggan pada Kantor Notaris dan PPAT Rachmansyah Purba, SH, M.Kn, di kota Pematangsiantar?

b. Bagaimana pengaruh Kualitas Pelayanan Jasa terhadap Kepuasan Pelanggan pada Kantor Notaris dan PPAT Rachmansyah Purba, SH, M.Kn, di kota Pematangsiantar?

\section{Tujuan Penelitian}

a. Untuk mengetahui gambaran Kualitas

Pelayanan Jasa dan Kepuasan Pelanggan pada Kantor Notaris dan PPAT Rachmansyah Purba,

$\mathrm{SH}, \mathrm{M} . \mathrm{Kn}$, di kota Pematangsiantar.

b. Untuk mengetahui pengaruh Kualitas Pelayanan Jasa terhadap Kepuasan Pelanggan pada Kantor Notaris dan PPAT Rachmansyah Purba, SH, M.Kn, di kota Pematangsiantar.

\section{Metode Penelitian}

Adapun desain penelitian yang digunakan dalam penelitian ini adalah Penelitian Kepustakaan (Library Research) dan Penelitian Lapangan (Field Research). Sumber data yang digunakan dalam penelitian ini adalah data primer dan data sekunder. Teknik pengumpulan data yang dilakukan penulis dalam penelitian ini adalah berupa kuesioner, wawancara, dokumentasi, dan observasi. Teknik analisa data yang digunakan dalam penelitian ini antara lain Uji Instrumen Penelitian, Teknik Analisa Deskriptif Kualitatif dan Teknik Analisa Deskriptif Kuantitatif.

\section{B. LANDASAN TEORI}

Menurut Robbins dan Mary (2010:7), manajemen yaitu melibatkan aktivitas-aktivitas organisasi dan pengawasan terhadap pekerjaan orang lain, sehingga pekerjaan tersebut dapat diselesaikan secara efisien dan efektif.

Menurut Daft (2002:8), fungsi manajemen terbagi 4 komponen, yaitu:

1. Perencanaan, yaitu penentuan sasaran sebagai pedoman kinerja organisasi di masa depan dan penetapan tugas-tugas serta alokasi sumberdaya yang diperlukan untuk mencapai sasaran organisasi.

2. Pengorganisasian, yaitu melibatkan penetapan tugas, pengelompokan tugas-tugas ke dalam departemen, dan alokasi bermacam-macam sumber daya ke dalam berbagai departemen.

3. Kepemimpinan, yaitu menciptakan nilai bersama, mengkomunikasikan sasaran kepada karyawan melalui organisasi, dan memberikan inspirasi agar karyawan berprestasi sebaikbaiknya.

4. Pengendalian, yaitu memantau aktivitas karyawan, menjaga organisasi agar tetap berjalan ke arah pencapaian sasaran, dan membuat koreksi bila diperlukan.

Pemasaran dalam suatu perusahaan memegang peranan yang sangat penting, karena pemasaran merupakan salah satu kegiatan yang dilakukan untuk mempertahankan kelangsungan hidup perusahaan, melakukan perkembangan terhadap perusahaan dan untuk pencapaian tujuan perusahaan dalam memperoleh laba. Menurut Kotler dan Kevin (2007:6), pemasaran adalah satu fungsi organisasi dan seperangkat proses untuk menciptakan, mengkomunikasikan, dan menyerahkan nilai kepada pelanggan dan mengelola hubungan pelanggan dengan cara yang menguntungkan organisasi dan para pemilik sahamnya.

Menurut Kotler dan Kevin (2007:6), manajemen pemasaran adalah sebagai seni dan ilmu memilih pasar sasaran dan mendapatkan, menjaga dan menumbuhkan pelanggan yaitu dengan menciptakan, menyerahkan dan mengkomunikasikan nilai pelanggan yang unggul. 
Pengertian jasa menurut Griffin dan Ronald (2006:277), yaitu produk-produk tak berwujud, seperti waktu atau keahlian, atau beberapa aktivitas, yang dapat dibeli. Menurut Wyckof dalam Nasution (2004:47), kualitas pelayanan jasa adalah tingkat keunggulan yang diharapkan dan pengendalian atas tingkat keunggulan tersebut untuk memenuhi keinginan pelanggan. Kualitas pelayanan jasa didefinisikan sebagai penyampaian jasa yang akan melebihi tingkat kepentingan pelanggan.

Menurut Parasuraman, Zeithaml dan Berry dalam Tjiptono dan Gregorius (2011:196), ada sepuluh kriteria umum atau standar yang menentukan kualitas pelayanan suatu jasa atau dimensi pokok kualitas jasa, yaitu:

1. Reliability (keandalan)

2. Responsiveness (ketanggapan)

3. Competence (kemampuan)

4. Access (mudah diperoleh)

5. Courtesy (keramahan)

6. Communication (komunikasi)

7. Credibility (dapat dipercaya)

8. Security (keamanan)

9. Understanding / knowing the customer (memahami pelanggan)

10. Tangibles (bukti nyata yang kasat mata)

Kesepuluh dimensi tersebut dapat disederhanakan menjadi lima dimensi sesuai dengan urutan tingkat kepentingan relatifnya yaitu :

1. Keandalan (Reliability), berkaitan dengan kemampuan perusahaan untuk menyampaikan layanan yang dijanjikan secara akurat sejak pertama kali.

2. Daya tanggap (Responsiveness), berkenaan dengan kesediaan dan kemampuan penyedia layanan untuk membantu para pelanggan dan merespon permintaan dengan segera.

3. Jaminan (Assurance), berkenaan dengan pengetahuan dan kesopanan karyawan serta kemampuan mereka dalam menumbuhkan rasa percaya (trust) dan keyakinan pelanggan (confidence).

4. Empati (Emphaty), berarti bahwa perusahaan memahami masalah para pelanggannya dan bertindak demi kepentingan pelanggan, serta memberikan perhatian personal kepada para pelanggan dan memiliki jam operasi layanan.

5. Bukti Fisik (Tangibles), berkenaan dengan penampilan fisik fasilitas layanan, peralatan/perlengkapan, sumber daya manusia, dan materi komunikasi perusahaan.

Menurut Kotler dan Kevin (2007:177), kepuasan adalah perasaan senang atau kecewa seseorang yang muncul setelah membandingkan kinerja (hasil) produk yang dipikirkan terhadap kinerja (hasil) yang diharapkan.

Kepuasan pelanggan terhadap suatu produk ataupun jasa, sebenarnya sesuatu yang sulit untuk didapat jka perusahaan jasa atau industri tersebut tidak benar-benar mengerti apa yang diharapkan oleh konsumen. Untuk produk dan layanan dengan kualitas yang sama, dapat memberikan tingkat kepuasan yang berbeda-beda bagi konsumen yang berbeda. Oleh karena itu, suatu perusahaan harus selalu memperhatikan kualitas produk maupun pelayanan yang diberikan kepada konsumen.

Menurut Umar (2003:15), ada 6 konsep yang umum dipakai dalam pengukuran kepuasan pelanggan, yaitu:

1. Kepuasan pelanggan keseluruhan; Caranya, yaitu dengan menanyakan pelanggan mengenai tingkat kepuasan atas jasa yang bersangkutan serta menilai dan membandingkan dengan tingkat kepuasan pelanggan keseluruhan atas jasa yang mereka terima dari para pesaing.

2. Dimensi kepuasan pelanggan; Prosesnya melalui empat langkah. Pertama, mengidentifikasi dimensi-dimensi kunci kepuasan pelanggan. Kedua, meminta pelanggan menilai jasa perusahaan berdasarkan item-item spesifik seperti kecepatan layanan atau keramahan staf pelayanan terhadap pelanggan. Ketiga, meminta pelanggan menilai jasa pesaing berdasarkan item-item spesifik yang sama. Keempat, meminta pelanggan menentukan dimensidimensi yang menurut mereka ada di kelompok penting dalam menilai kepuasan pelanggan keseluruhan.

3. Konfirmasi harapan; Pada cara ini, kepuasan tidak diukur langsung, namun disimpulkan berdasarkan kesesuaian/ketidaksesuaian antara harapan pelanggan dengan kinerja aktual jasa yang dijual perusahaan.

4. Minat pembelian ulang; Kepuasan pelanggan diukur berdasarkan apakah mereka akan mengadakan pembelian ulang atas jasa yang sama yang dia konsumsi.

5. Kesediaan untuk merekomendasi; Cara ini merupakan ukuran yang penting, apalagi bagi jasa yang pembelian ulangnya relatif lama, seperti jasa pendidikan tinggi.

6. Ketidakpuasan pelanggan; Dapat dikaji, misalnya dalam hal komplain.

Menurut Lupiyoadi dan Hamdani (2006:158)

ada 5 faktor utama dalam menentukan tingkat kepuasan pelanggan, yaitu:

1. Kualitas Produk, yaitu pelanggan akan puas bila hasil evaluasi mereka menunjukkan bahwa produk atau jasa yang mereka gunakan berkualitas.

2. Kualitas Pelayanan, yaitu pelanggan akan merasa puas bila mendapatkan pelayanan yang baik atau yang sesuai dengan harapan.

3. Emosional, yaitu pelanggan akan merasa bangga dan mendapatkan keyakinan bahwa orang lain akan kagum bila menggunakan produk yang bermerek dan cenderung mempunyai kepuasan yang lebih tinggi.

4. Harga, yaitu produk atau jasa yang mempunyai kualitas yang sama tetapi menetapkan harga yang murah akan memberikan nilai yang lebih tinggi kepada pelanggannya.

5. Biaya, yaitu pelanggan akan merasa puas apabila tidak perlu mengeluarkan biaya tambahan atau tidak perlu membuang waktu 
untuk mendapatkan suatu produk atau jasa tersebut.

Menurut Wyckof dalam Nasution (2004:47), kualitas pelayanan jasa adalah tingkat keunggulan yang diharapkan dan pengendalian atas tingkat keunggulan tersebut untuk memenuhi keinginan pelanggan. Kualitas pelayanan jasa didefinisikan sebagai penyampaian jasa yang akan melebihi tingkat kepentingan pelanggan.

Dengan adanya kemampuan penyedia jasa untuk menyampaikan jasa melebihi tingkat kepentingan pelanggan maka dapat menimbulkan tingkat kepercayaan pelanggan terhadap penyedia jasa. Selain hal tersebut, penyedia jasa harus mampu berinteraksi lebih baik lagi dengan para pelanggannya, yang pada akhirnya akan menciptakan dan meningkatkan kepuasan pelanggan.

\section{PEMBAHASAN}

\section{Analisa}

\section{a. Analisa Deskriptif Kualitatif}

\section{1) Gambaran Kualitas Pelayanan Jasa}

Kualitas pelayanan jasa adalah penyampaian jasa yang akan melebihi tingkat kepentingan pelanggan yaitu kesenjangan antara ekspektasi atau keinginan pengguna jasa dengan apa yang dirasakan oleh mereka. Salah satu dimensi dari kualitas pelayanan jasa yang diterapkan dalam Kantor Notaris dan PPAT Rachmansyah Purba, SH, M.Kn adalah keandalan (reliability). Dimana pada indikator ini yaitu bagaimana pelanggan terhadap tindakan Notaris dan PPAT serta pegawainya mengatasi ketepatan waktu ketika menepati janji dalam penyelesaian masalah serta kesesuaian pelaksanaan yang dirasakan oleh pelanggan yang dapat dipertanggungjawabkan sehingga menimbulkan kepuasan, kepercayaan dan kesetiaan bagi pelanggannya.

Berdasarkan hasil penelitian, kualitas pelayanan jasa yang ada pada Kantor Notaris dan PPAT Rachmansyah Purba, SH, M.Kn di Kota Pematangsiantar dinilai baik dengan nilai rata-rata 3,79. Akan tetapi masih terdapat kelemahan pada dimensi keandalan (reliability), yaitu dari segi ketepatan waktu dalam penyelesaian masalah. Dimensi daya tanggap (responsiveness), yaitu dari segi kecepatan pegawai untuk menanggapi keluhan masalah para pelanggan. Dimensi jaminan (assurance), yaitu dari segi kenyamanan dalam pengurusan. Dimensi empati (emphaty), yaitu dari segi pemahaman kebutuhan secara spesifik, minat untuk menggunakan jasa, dan perhatian memberi solusi. Dan yang terakhir bukti fisik (tangibles) yaitu dari segi fasilitas, kerapian pegawai dan bangunan kantor yang masih dibawah nilai rata-rata.

\section{2) Gambaran Kepuasan Pelanggan}

Kepuasan pelanggan adalah respon dari perilaku yang ditunjukkan oleh pelanggan dengan membandingkan antara kinerja atau hasil yang dirasakan dengan harapan. Apabila hasil yang dirasakan dibawah harapan, maka pelanggan akan kecewa, kurang puas bahkan tidak puas, namun sebaliknya bila sesuai dengan harapan, pelanggan akan puas dan bila kinerja perusahaan melebihi harapan, pelanggan akan sangat puas.

Pengukuran tingkat kepuasan pada Kantor Notaris dan PPAT Rachmansyah Purba, SH, M.Kn di kota Pematangsiantar yaitu dengan melakukan penyebaran kuesioner, dimana pelanggan dapat menempatkan keluhan serta perasaan apa yang dirasakan selama melakukan pengurusan dan menerima pelayanan serta dapat memberikan saran/kritik yang membangun demi pelayanan jasa hukum untuk perlindungan hukum itu sendiri.

Berdasarkan hasil penelitian, kepuasan pelanggan yang ada pada Kantor Notaris dan PPAT Rachmansyah Purba, SH, M.Kn di Kota Pematangsiantar dinilai puas dengan nilai rata-rata 3,61. Akan tetapi masih terdapat kelemahan pada prosedur pelayanan, persyaratan pelayanan, kedisiplinan petugas pelayanan, tanggung jawab petugas pelayanan, kepastian biaya pelayanan dan kenyamanan lingkungan yang masih dibawah nilai rata-rata.

\section{b. Analisa Deskriptif Kuantitatif}

\section{1) Regresi Linier Sederhana}

Persamaan hasil regresi linier sederhana dapat dilihat dari tabel di bawah ini:

Tabel 2

Hasil Regresi Linier Sederhana

\begin{tabular}{|c|c|c|c|c|c|c|}
\hline \multicolumn{7}{|c|}{ Coelficentst } \\
\hline \multirow{2}{*}{\multicolumn{2}{|c|}{ Mades }} & \multicolumn{2}{|c|}{$\begin{array}{c}\text { Unstandardized } \\
\text { Comflicerth }\end{array}$} & \multirow{2}{*}{$\begin{array}{l}\text { Standardized } \\
\text { Coefficients }\end{array}$} & \multirow[t]{2}{*}{$\uparrow$} & \multirow[t]{2}{*}{ Sig. } \\
\hline & & $B$ & Stri Erint & & & \\
\hline \multirow[b]{2}{*}{1} & (Conttant) & 24.474 & 3273 & & 3.901 & .000 \\
\hline & $\begin{array}{l}\text { Kuaitas } \\
\text { Pelajanan_asia }\end{array}$ & 519 & 110 & 605 & 4.731 & 000 \\
\hline
\end{tabular}

a. Dupensont Varabic Kesuasan Perangean

Sumber: data primer hasil pengolahan SPSS versi 20

Dari hasil tabel 2 di atas, persamaan regresi yang diperoleh yaitu sebagai berikut: $\hat{\mathrm{Y}}=24,474+$ 0,519 . Persamaan tersebut menjelaskan bahwa terdapat pengaruh yang positif antara kualitas pelayanan jasa $(\mathrm{X})$ terhadap kepuasan pelanggan $(\mathrm{Y})$ pada Kantor Notaris dan PPAT Rachmansyah Purba, SH, M.Kn di Kota Pematangsiantar. Semakin baik kualitas pelayanan jasa maka semakin puas pelanggan. Sebaliknya, apabila kualitas pelayanan tidak baik maka kepuasan pelanggan akan menurun.

\section{2) Analisa Koefisien Korelasi dan Koefisien} Determinasi

Untuk menghitung kekuatan hubungan kualitas pelayanan jasa terhadap kepuasan pelanggan, dilakukan dengan menggunakan bantuan SPSS Versi 20 yaitu dapat dilihat melalui tabel berikut ini: 
Tabel 3

Hasil Koefisien Korelasi

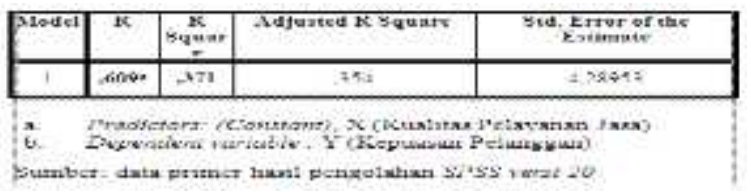

Dari besarnya nilai analisa korelasi yaitu 0,609 menunjukkan bahwa hubungan yang kuat antara kualitas pelayanan jasa dan kepuasan pelanggan yang diteliti di Kantor Notaris dan PPAT Rachmansyah Purba, SH, M.Kn di Kota Pematangsiantar. Sedangkan Nilai Koefisien Determinasi (KD) yaitu $0,371 \times 100 \%=37,1 \%$. Hal ini berarti 37,1\% variabel kepuasan pelanggan (Y) dijelaskan oleh variabel kualitas pelayanan jasa (X). Sedangkan 62,9\% dijelaskan oleh faktor-faktor lain yang tidak dibahas pada penelitian ini seperti Sikap, Loyalitas Pelanggan, motivasi pelanggan, persepsi kualitas dan faktor lainnya diluar model.

\section{3) Pengujian Hipotesis}

Dari hasil uji t tabel 2 di atas, diperoleh $t_{\text {hit }}$ sebesar 4,731 sedangkan $t_{\text {tabel }}$ pada tingkat signifikansi $\alpha=0,05$ adalah sebesar 2,024. Oleh karena $t_{\text {hit }}>t_{\text {tabel }}$, maka $H_{o}$ ditolak dan $H_{a}$ diterima, yang artinya menunjukkan bahwa kualitas pelayanan jasa berpengaruh positif dan signifikan terhadap kepuasan pelanggan pada Kantor Notaris dan PPAT Rachmansyah Purba, SH, M.Kn di Kota Pematangsiantar.

\section{EVALUASI}

\section{a. Kualitas Pelayanan}

Berdasarkan dimensi yang digunakan dan hasil penelitian yang diperoleh dapat dijelaskan bahwa kualitas pelayanan jasa pada Kantor Notaris dan PPAT Rachmansyah Purba, SH, M.Kn di Kota Pematangsiantar dapat dikatakan baik, baik dari segi reliability (keandalan), responsiveness (daya tanggap), assurance (jaminan), emphaty (empati) dan tangibles (bukti fisik). Hal tersebut dibuktikan dengan nilai rata-rata dari sisi kualitas pelayanan jasa sebesar 3,79 yang dinilai baik.

Namun ada beberapa aspek walaupun dinilai baik masih lebih rendah dari aspek-aspek yang lain, yaitu Dimensi keandalan (reliability), pada pertanyaan ketepatan waktu dalam menyelesaikan masalah berada pada nilai rata-rata 3,73. Hal ini disebabkan Kantor Notaris dan PPAT Rachmansyah Purba, SH, M.Kn di Kota Pematangsiantar belum memberikan pelayanan dengan segera, akurat dan memuaskan. Seharusnya pelanggan diberikan suatu surat keterangan yang akurat agar tidak terjadi terlambatnya penyelesaian masalah itu sendiri.

Dimensi daya tanggap (responsiveness), pada pertanyaan kecepatan pegawai untuk menanggapi keluhan masalah para pelanggan berada pada nilai rata-rata 3,70. Hal ini disebabkan kurangnya pengetahuan pegawai terhadap pelayanan jasa hukum dan terkadang notaris yang tidak berada di tempat. Dimensi jaminan (assurance), pada pertanyaan kenyamanan dalam pengurusan berada pada nilai rata-rata 3,78. Hal ini disebabkan masih ada pegawai yang belum mampu melayani pelanggan dengan ramah, yang menyebabkan pelanggan tidak nyaman untuk melakukan pengurusan.

Dimensi empati (emphaty), pada pertanyaan pemahaman kebutuhan secara spesifik dan minat untuk menggunakan jasa berada pada nilai rata-rata masing-masing 3,70 serta pertanyaan perhatian untuk memberi solusi berada pada nilai rata-rata 3,75. Hal ini disebabkan kurangnya komunikasi yang baik pegawai dengan pelanggan, perhatian pribadi dalam memenuhi kebutuhan pelanggan. Dimensi bukti fisik (tangibles) pada pertanyaan fasilitas dan kerapian pegawai dengan nilai rata-rata masingmasing 3,70 dan bangunan kantor yang memiliki nilai rata-rata 3,58. Hal ini disebabkan oleh fasilitas yang cukup memadai, semua pegawai tidak mempunyai pakaian yang seragam dan terlihat warna warni, serta bangunan yang kurang luas dan ruang tunggu yang minim.

\section{b. Kepuasan Pelanggan}

Kepuasan pelanggan menjadi tolak ukur pencapaian tujuan suatu organisasi khususnya perusahaan jasa. Semakin puas pelanggan maka semakin mudah juga organisasi mencapai tujuannya. Begitu juga dengan Kantor Notaris Rachmansyah Purba SH, M.Kn di Kota Pematangsiantar. Indikator kepuasan pelanggan yang ada pada Kantor Notaris Rachmansyah Purba SH, M.Kn di Kota Pematangsiantar dapat dikatakan baik. Dilihat dari kuesioner yang dibagikan kepada responden, secara keseluruhan dinilai puas dengan nilai rata-rata 3,61.

Namun tentunya ada indikator-indikator yang harus menjadi perhatian, terutama dari segi prosedur pelayanan, persyaratan pelayanan, kedisiplinan petugas pelayanan, tanggung jawab petugas pelayanan, kepastian biaya pelayanan dan kenyamanan lingkungan. Dalam prosedur pelayanan berada pada rata-rata 3,43. Selanjutnya untuk indikator persyaratan pelayanan berada pada ratarata 3,53. Indikator kedisiplinan petugas pelayanan berada pada rata-rata 3,45 . Indikator tanggung jawab petugas pelayanan berada pada rata-rata 3,6. Indikator kepastian biaya pelayanan berada pada rata-rata 3,58. Dan indikator kenyamanan lingkungan berada pada rata-rata 3,60. Hal ini disebabkan prosedur serta persyaratan pelayanan yang tidak menggunakan SOP, tidak adanya hukuman bagi pegawai yang terlambat, tanggung jawab yang masih kurang, dan biaya yang terkadang berbeda dari yang telah ditetapkan sebelumnya karena adanya tambahan pelayanan yang lainya yang belum disampaikan kepada pelanggan. 


\section{KESIMPULAN DAN SARAN}

\section{Kesimpulan}

a. Kualitas pelayanan jasa berpengaruh terhadap kepuasan pelanggan, hal ini terlihat dari hasil pengujian regresi yang menunjukkan tanda positif pada persamaan sebagai berikut: $\widehat{\mathrm{Y}}=$ $24,474+0,519 \mathrm{X}$, artinya semakin baik kualitas pelayanan jasa maka pelanggan akan semakin lebih puas.

b. Dengan nilai $r=0,609$ terdapat hubungan yang kuat antara variabel $\mathrm{X}$ dan variabel $\mathrm{Y}$. Sedangkan Nilai Koefisien Determinasi (KD) yaitu $0,371 \times 100 \%=37,1 \%$. Hal ini berarti 37,1 $\%$ variabel kepuasan pelanggan $(\mathrm{Y})$ dijelaskan oleh variabel kualitas pelayanan jasa (X). Sedangkan $62,9 \%$ dijelaskan oleh faktor-faktor lain yang tidak dibahas pada penelitian ini seperti Sikap, Loyalitas pelanggan, motivasi pelanggan, persepsi kualitas dan faktor lainnya diluar model.

c. Dari hasil pengujian thit, diketahui bahwa nilai thitung $(4,731)>$ tabel $(2,024)$ sehingga Ho ditolak dan Ha diterima. Hasil tersebut menunjukkan bahwa kualitas pelayanan jasa berpengaruh positif terhadap kepuasan pelanggan pada Kantor Notaris dan PPAT Rachmansyah Purba, SH, M.Kn di Kota Pematangsiantar.

\section{Saran}

a. Keandalan (Reliability), yaitu Kantor Notaris dan PPAT perlu didukung oleh sistem pengarsipan yang handal. Selain faktor akurasi dan keamanan, sistem pengarsipan dibutuhkan untuk menjamin pengelolaan dokumen yang terintegrasi. Perumusan tugas, hak, wewenang, dan tanggung jawab yang jelas bagi setiap pegawai, pembuatan kartu kendali sebagai alat untuk memantau proses penyelesaian suatu akta, dan penataan arsip dengan memilih metode penyimpanan yang dirasakan paling sesuai dengan kantor agar tidak ada lagi penyimpanan berkas yang kurang baik, sehingga penemuan kembali surat-surat tidak lagi dengan menggunakan atau didasarkan pada ingatan saja. Daya tanggap (responsiveness), yaitu dalam hal ini Kantor harus cepat tanggap memberikan penjelasan yang jelas dan terperinci mengenai masalah pelanggan agar tidak kalah dengan banyak pesaing. Jaminan (assurance), yaitu para pegawai dituntut untuk mampu bekerja secara profesional dalam bidang pelayanan sebagai upaya untuk memperbaiki citra perusahaan, sekaligus kinerja Sumber Daya Manusia serta upaya untuk memperbaiki tingkat pelayanan perusahaan kepada pelanggan yang selama ini belum dilaksanakan sebagaimana mestinya.

b. Empati (empathy), yaitu meliputi kemampuan berkomunikasi dan perhatian secara individual dengan para pelanggan yang harus ditingkatkan oleh setiap pegawai Kantor Notaris dan PPAT Rachmansyah Purba SH, M.Kn di Kota Pematangsiantar. Bukti Fisik (tangibles), dalam hal ini yaitu penataan kembali tata ruang sehingga situasi pada kantor mendorong gairah kerja para pegawai serta memberikan kenyamanan bagi para tamu yang datang. Dilihat dari sisi fasilitas yaitu perlengkapan, yaitu sebagai penyedia layanan administrasi publik yang didukung dengan sistem pembuatan akta dengan sistem komputerisasi serta sistem hasil dari pembuatan akta dengan cetakan yang bagus, Kantor Notaris Rachmansyah Purba SH, M.Kn di Kota Pematangsiantar sampai saat ini masih memiliki 5 orang pegawai, tetapi diharapkan untuk di masa yang akan datang agar menambah pegawai, agar mampu mempercepat proses dari pelayanan itu sendiri.

c. Agar kepuasan pelanggan tetap bertahan maka hal yang harus dilakukan yaitu membuat Standar Operation Procedur (SOP) untuk pencapaian efektifitas dan efisiensi yang lebih baik lagi, sarana komunikasi Kantor Notaris dan PPAT Rachmansyah Purba SH, M.Kn di Kota Pematangsiantar terhadap para pelanggan adalah dalam hal penyampaian cara-cara atau syaratsyarat yang harus dilakukan jika akan membuat suatu akta-akta otentik yang berhubungan dengan Notaris maupun akta-akta otentik yang berhubungan dengan pertanahan. Pentingnya membuat peraturan yang lebih mengikat untuk meningkatkan disipin dan dapat membina kesantunan di lingkungan kerja antar sesama pegawai dan terutama pelanggan menjadi lebih baik, perlunya peningkatan, dan membuat tarif atau biaya yang sesuai, agar pelanggan tidak merasa bingung dan berbelit-belit dalam melakukan pengurusan. Jika ada biaya tambahan hendaknya diberitahukan kepada pelanggan dengan segera, agar tidak terjadi kekeliruan untuk ke depannya. Untuk memberikan kenyamanan bagi para pelanggannya Kantor Notaris dan PPAT Rachmansyah Purba SH, M.Kn di Kota Pematangsiantar juga berupaya untuk meningkatkan kebersihan lingkungan kerja agar pelanggan merasa nyaman saat melakukan pengurusan.

d. Penelitian/survey kepuasan pelanggan perlu dilanjutkan dan dikembangkan oleh peneliti lain dengan cara menambah dan mengembangkan parameter yang telah ada sebelumnya dalam rangka mendukung pelaksanaan pelayanan jasa di bidang hukum pada Kantor Notaris Rachmansyah Purba SH, M.Kn di Kota Pematangsiantar.

\section{E. DAFTAR PUSTAKA}

Daft, Richard L. 2002. Manajemen. Jilid 1. Edisi Kelima. Jakarta: Erlangga.

Griffin, Ricky W. dan Ronald J. Ebert. 2006. BISNIS. Jilid 1. Edisi Kedelapan. Jakarta: Erlangga.

Kotler, Philip dan Kevin Lane Keller. 2007. Manajemen Pemasaran. Jilid 1. Edisi 12. Jakarta: PT. Indeks. 
2007. Manajemen Pemasaran. Jilid 2. Edisi 13. Jakarta: PT. Indeks.

Lupiyoadi, Rambat dan A. Hamdani. 2006. Manajemen Pemasaran Jasa. Edisi 2. Jakarta: Salemba Empat.

Nasution, M. Nur. 2004. Manajemen Jasa Terpadu. Bogor: Ghalia Indonesia.
Robbins, Stephen dan Mary Coulter. 2010. Manajemen. Jilid 1. Edisi Kesepuluh. Jakarta: Erlangga.

Umar, Husein. 2003. Metode Riset Perilaku Konsumen Jasa. Jakarta: Ghalia Indonesia. 